\title{
Facilitating Therapeutic Expression and Communication through Play
}

\author{
Christina D. Brown
}

Child Life, Education and Creative Arts Therapy Department, The Children's Hospital of Philadelphia, Philadelphia, Pa., USA

\section{Key Words \\ Play · Therapeutic play $\cdot$ Child life $\cdot$ Child life specialist}

\begin{abstract}
Objective: To present several examples that illustrate the effectiveness of play interventions in a hospital context facilitated by child life specialists and other health care providers. Clinical Presentation and Intervention: Specific examples include children between the ages of 4 and 10 with serious illnesses (cancer, cystic fibrosis, heart disease) and those having experienced the death of a loved one. Interventions include child-directed play as a therapeutic modality. Conclusion: The opportunities afforded by play and creative arts for self-expression, mastery, and control are of paramount importance for children experiencing the anxiety or psychological trauma often associated with a serious illness or with the death of a loved one. $\quad$ Copyright $\odot 2007$ S. Karger AG, Basel
\end{abstract}

\section{Introduction}

Play has been observed as a universal behavior in children. By the time they reach 6 years of age, children are likely to have engaged in over $15,000 \mathrm{~h}$ of play [1]. It is well established that play supports a child's cognitive development, socialization, physical abilities; in fact every facet of growth and development is supported by the child's involvement in play. However, for children who may be terminally ill themselves, or for siblings experiencing the illness or death of a brother or sister, play and the need for play take on a different significance. Play is recognized as essential in children's ability to cope with stress and is a primary means of managing emotionally challenging experiences [2-4]. The use of play as a therapeutic modality enables children to express thoughts and feelings, assimilate reality, resolve internal conflicts, achieve mastery, and cope effectively [5]. The opportunities afforded by play for self-expression, mastery, and control are of paramount importance for children experiencing the anxiety or psychological trauma often associated with a serious illness or with the death of a loved one. To aid in an understanding of the value of play, the following defining characteristics are suggested [6, 7]:

- play is internally controlled;

- play is intrinsically motivated;

- play is actively engaging;

- play is internally real;

- play is pleasurable.

'True' play is characterized by the child having ultimate control over play, determining for him or herself what themes or concepts will be explored to meet his or her own idiosyncratic needs or situational interests [8]. Such play is also known as child-centered or child-directed play. Conversely, 'true' play cannot be realized if the adult controls the objects or themes, if specific time limits or expectations are imposed, or if the play is adult-

\section{KARGER}

Fax +41613061234

E-Mail karger@karger.ch

www.karger.com
(C) 2007 S. Karger AG, Basel

1011-7571/07/0167-0027\$23.50/0

Accessible online at:

www.karger.com/mpp
Christina D. Brown

The Children's Hospital of Philadelphia

Child Life Department, Room 8540, 34th St. and Civic Center Blvd.

Philadelphia, PA 19104 (USA)

Tel. +1 215590 2001, Fax +1 215590 2023, E-Mail brownc@email.chop.edu 
directed to, for example, impart specific concepts or knowledge. Bolig [7] also differentiates between structured and unstructured play, suggesting that unstructured play, which is open-ended and fluid, is more therapeutic for children than structured or directed play. Thus, expressive, child-directed play is considered the most effective in promoting self-healing and is particularly useful with children under stress.

\section{Principles and Techniques}

The following principles and case examples illustrate valuable techniques for working with ill or grieving children. These techniques can be utilized by child life specialists, other members of the health care team, teachers or counselors, and even family members to facilitate healthy expression and development with children of all ages. A child life specialist is trained to use play and other forms of communication to support the psychosocial needs of children, usually in health care settings. For more information about the child life profession contact the Child Life Council [9].

\section{Principle 1: Play Creates an Atmosphere of Normalcy, Familiarity, and Acceptance}

Circumstances such as severe illness, curative or palliative care, or the death of a loved one represent an $a b$ normal or unfamiliar experience for children. The child's lack of past experience, as well as cognitive immaturity and undeveloped coping skills result in a challenge to his/ her emotional equilibrium. Play can contribute to a feeling of normalcy and assuage feelings of insecurity resulting from separation from family or friends, being subjected to frightening health care routines, or even being placed in a new family constellation. In play, children can be themselves, and if play is accompanied by messages from empathetic adults that it is noticed and valued, then the child feels accepted and validated.

\section{Case Example}

Ten-year-old Eric's favorite play activity was Playmobile ${ }^{\circledR}$ (small plastic figurines in sets such as pirate ship, castle, airport). He owned dozens of 'people' and various props and would bring many with him to the hospital each time he was admitted. He adored his time with the child life specialist each day, telling his mother she could 'take a break now' and spent a much coveted and uninterrupted hour at play. He made up fanciful, detailed stories for the characters to act out, many involving danger, es- cape and victory. Occasionally, Eric would want to paint or pursue other activities but most days he reverted back to his Playmobile play. Toward the end of his life, and in spite of progressive symptoms and weakness, Eric requested that the child life specialist continue to visit and the Playmobile figures continued to populate the bedside table. This particular play made Eric feel more 'normal' than anything else could. It was familiar and comforting and, because of the projective quality of the figures, therapeutically expressive as well. Upon entering his room on the day that would ultimately be his last, Eric weakly exclaimed to the child life specialist, 'thank goodness you're here, I reeeeally need to play.'

\section{Principle 2: Children Communicate through Play}

An adult's conventional mode of expressing thoughts and feelings is that of verbal communication. Children, however, have not developed the same cognitive and verbal skills and thus are naturally more comfortable and capable of expressing themselves through their play. So, in effect, play is to children what verbalization is to adults. Play is symbolic language that reveals a child's self-perception and feelings and reactions to experiences, wishes, wants and needs [10].

\section{Case Example 1}

Four-year-old Jessica attended a grief support group following the death of her older brother. During the first session, Jessica's play was initially shy and involved the socially acceptable theme of nurturing and feeding a baby doll. According to her mother, Jessica had always been a quiet little girl, not one to show her emotions, never rambunctious. Understanding the value of child-directed play, the bereavement facilitator allowed Jessica to choose her own play activities and maintained a supportive physical and emotional environment. Soon Jessica gravitated to the toy shelf and retrieved several large plastic dinosaurs. She put the dinosaurs on the table, looked to see if there was any reaction from the therapist, and went back to her baby doll play. After a few more minutes, she returned to the dinosaurs and orchestrated a biting, clawing fight among the creatures. She did so very calmly and quietly, but with clear intent. The dinosaurs, by their very nature, and the supportive approach of the therapist, empowered Jessica to express feelings of anger and aggression.

This principle is applied effectively to the use of art as well. Through art, such as picture drawing, sculpture or collage, a child can access and give form to inner fantasies, concerns, meaning and even resources related to the experience [11]. 
Case Example 2

Angie, 6 years of age and suffering from leukemia, loved to draw pictures. Like many young girls, her pictures were often of flowers, rainbows and sunshine. Though the doctors had assured her mother that treatment options had been exhausted and Angie was dying, her mother actively refused to allow any conversation about the seriousness of her illness or any mention of death. As is very often the case however, Angie was not ignorant of her prognosis and yet she also understood that her mother was not open to any conversation or questions about death. Hence drawing represented a more natural and 'safer' way to express her thoughts and feelings. While her drawings continued to contain sunshine and rainbows, she also began to draw angels, complete with halos and wings and big smiles, to her scenes. Upon discussion with the art therapist and medical team, her mother realized that Angie was already 'talking' about dying and ultimately was able to more openly engage in mutually supportive communication. Art, in addition to being a therapeutic activity, lends itself to legacy building and Angie's art provided her family with many precious keepsakes.

Principle 3: Play and Creative Expression Are the Child's Major Defenses against Helplessness and Psychological Trauma

Perhaps the most significant benefit of play to children experiencing stress involves the potential for catharsis and mastery. Children readily use play as their symbolic language of self-expression, representing the most dynamic and self-healing process in which children can engage $[12,13]$. The well-known play therapist Virginia Axline [14] expresses the potential for catharsis and emotional release by the 'playing out' or reenacting of a particular stressful experience. Mastery is supported as the child is in control of the play and thus moves out of the passive role and into an active one.

In all the previous examples, Eric, Jessica, and Angie counteracted their feelings of helplessness and were readily able to express themselves through their play. They were driven by their own desire to move toward mastery and self-actualization and identified the processes that would assist them in their psychological healing. The presence of a caring, sensitive, and empathic adult assisted in facilitating the process.
Principle 4: A Therapeutic Working Relationship with Children Is Best Established through Play

The facilitation of therapeutic, child-centered play requires that the adult experience a genuine feeling of warmth and caring for the child that is unconditional [14]. Such a relationship maximizes the child's ability to be fully himself/herself and to pursue mastery and accomplishment. In the health care setting, child life specialists are employed specifically to facilitate therapeutic play, self-expression and coping in children with special needs and their siblings. In an environment that can be overwhelming and where so many experiences are negative, play provides comfort through familiarity as well as an emotional outlet for the child. Because the relationship is rooted in positive regard and nonthreatening playbased interactions, the child life specialist is in a position to quickly establish a therapeutic relationship. This relationship supports children's abilities to let down their defenses and engage in play and other expressive activities.

\section{Case Example}

Tyree's hospital stay required frequent painful procedures and separation from his working mother. At 9 years of age, Tyree's coping skills were being severely challenged. He resisted nursing care by lashing out violently, both physically and verbally. The staff were extremely frustrated and running out of patience. Tyree's 'out of control' behavior was directly related to his feeling that he had no control over his situation. His refusal to cooperate with his care and his acting out were manifestations of his natural feelings of anger and represented an attempt to gain some sense of control. Due to staff turnover, the child life specialist position was vacant during Tyree's first 2 weeks of admission during which his acting out behaviors escalated. He frequently picked fights with other children or destroyed playroom equipment, causing the nurses to deny him playroom privileges. When the new child life specialist was hired, the staff asked in desperation how she could help Tyree. She was able to form a nonthreatening and accepting relationship with Tyree, and recognizing that play provided a much-needed outlet for Tyree's strong emotions, offered play activities that specifically provided for aggressive and physically active play. In addition to target throwing and carpentry activities, Tyree responded enthusiastically to miniature figurine play. Using the hundreds of small plastic-molded figures available in the playroom (e.g. soldiers, wild animals, cowboys and Indians, knights in armor), he independently played out an extensive war 
among the figures, a play activity he engaged in day after day. Miniature play has been shown to help ameliorate children's feelings of vulnerability, reducing the overwhelming world of adults to a manageable size [15] and puts control literally in the hands of the child. Tyree's frequent participation in this type of play provided appropriate outlets for anger and his increased feelings of control resulted in gradually improving cooperation and appropriate socialization.

\section{Play and the Grieving Child}

Bereavement specialist William Worden suggests that mourning is necessary and that there are certain tasks that must be accomplished for equilibrium to be reestablished so that the process of mourning can be resolved [16]. Similarly, Wolfelt [17] describes 6 reconciliation needs of mourning in children:

- acknowledge the reality of the death;

- experience the pain of the loss;

- convert the relationship with the person who has died from one of presence to one of memory;

- develop a new self-identity based on a life without the person who died;

- relate the experience of death to a context of meaning;

- receive ongoing support from others.

Play serves a significant role when a child is grieving and assists in meeting many of these reconciliation needs. It is suggested that play is an effective and even necessary outlet for grieving children.

\section{Case Example 1}

Five-year-old Alicia had experienced the death of her father and brother in a house fire. She attended a series of bereavement support group sessions sponsored by the children's hospital. She was observed several times playing at the sand table, burying small toys and figurines over and over again. At one point, Alicia called down into the sand, as if to the figure she had buried, 'Can you breathe down there; do you need some water?' The child life specialist was able to reassure Alicia that when someone dies their body does not breathe or eat or drink any longer, thus supporting Alicia's cognitive understanding of the death of her father and brother.

A central task of grieving is to 'feel the feelings' associated with the loss. Play and creative arts activities are central to this task for children in their ability to enhance self-expression. As previously established, play is the nat- ural mode of communication for children. Play effectively allows children to express fantasies, anxieties and defenses.

\section{Case Example 2}

For 6 months, 7-year-old Zachary had attended a grief support group for children whose parents had died. He actively participated in the group, reminiscing about his father, playing with the other children, and had developed a trusting relationship with the group facilitators. While he shared that his father had died in a car accident, he had never admitted that his father had been an abusive alcoholic and had been drunk when the accident occurred. One evening, after having been read a story about feelings, the children chose to play with Playdoh ${ }^{\circledR}$ modeling clay. They pounded and pummeled the clay and some talked about how they liked to play with Playdoh when they were feeling angry, as the storybook had suggested. Zachary had positioned himself at a corner table and was seen to have created an elaborate scene with Playdoh cars and a figure lying on the road with a pool of red clay under his head. There were miniature clay beer cans and a cowboy boot in the middle of the road beside a crumpled blue car. The group facilitator wandered over and sat next to Zachary observing simply, 'I see that you've created a picture with your Playdoh.' Zachary proceeded to tell of his knowledge that his father had been drunk and that he was very angry at him for 'doing that to me and my mother'. This represented a significant breakthrough for Zachary, facilitated by the therapist's willingness to trust Zachary's own process and timeline.

\section{The Adult's Role in Play}

As was illustrated in the case of Zachary, the adult's role in the play of a child is often one of facilitator and supporter. The therapeutic benefits of play are maximized when the play is child-directed rather than adultdirected. In other words, the child is encouraged and permitted to lead the way; the adult does not push, pull, or predetermine the direction of the play. While the role of the adult does vary when therapy or education is the goal, the discussion here focuses on the therapeutic and developmentally supportive values of play, not on play as therapy or on the use of play techniques to teach the child about illness, death, or other concepts. The adult who serves as play facilitator and supporter should:

- make available a variety of developmentally appropriate toys and materials that stimulate play; 
- provide toys that promote creative use and the expression of feelings;

- respect the child's work by not interrupting, hurrying or directing the play;

- maintain a comfortable, clean, safe, nonthreatening environment;

- support the child's initiative during play rather than controlling how he/she plays;

- allow the child to use the materials in the way that he/ she wishes;

- encourage the child to do things on his/her own, resisting temptation to offer assistance when it is not needed;

- use reflective and attending techniques to support the child's play rather than carrying on a running dialogue or asking numerous questions.

It is not unusual for adult-child interactions to be peppered with questions asked of the child. Children learn early on that questions posed by an adult call for an answer. The process of considering a question and formulating an answer is a conscious, mental process, whereas play is more a subconscious or gut level activity. To answer a question during play, a child must in effect interrupt his/her process to shift between gut and brain. For this reason, it is recommended that adults resist asking questions during the child's play, allowing the play to be as child-directed as possible. Instead, simple reflective statements, used thoughtfully and sparingly, can encourage the child's play and demonstrate support and understanding rather than intrusion or direction. Consider these examples of reflective dialogue: 'I see the doll is getting a shot ...' rather than, 'Why does the doll have to get a shot? Does it hurt? Did you get a shot?', or 'It looks like the person in that picture has lots and lots of tears ...' rather than, 'Why is the boy in your picture crying?'

For the child who may be too sick or weak to play, vicarious enjoyment and expression may be accomplished by playing for the child. If the child can nod in response to questions or can speak, she can direct the adult's play or art by choosing actions or content of conversation (e.g. with doll figures or puppets played with by the adult) or even by resting a hand on the adult's while painting.

\section{Recommended Play Materials}

Play materials may be categorized in a number of ways, including age appropriateness, learning goals, and use or function. If, as has been presented, toys are a child's words and play is his/her language, toys and materials (words) should be selected that facilitate the child's expression by providing a wide range of play activity (language). Play therapy expert Garry Landreth [18] offers the following guidelines for selecting toys and materials that will serve as a medium for children to express feelings, explore relationships, and increase self-understanding. Consider whether or not the toys and materials

- stimulate a wide range of creative expression;

- facilitate a wide range of emotional expression;

- engage children's interests;

- facilitate expressive and exploratory play;

- allow exploration and expression without verbalization;

- facilitate success without prescribed structure;

- allow for noncommittal play;

- have a sturdy construction for active use.

In the health care setting, it is also essential that the toys and materials allow for safe and effective infection control.

Suggested materials for children affected by hospital/ hospice care, loss, and bereavement experiences include:

- real-life toys: e.g. doll family, doll house, puppets, cars, doctor kits, kitchen furniture and equipment, telephone;

- acting-out/aggressive-release toys: punching bag or 'bop bag'; miniature figures such as toy soldiers, wrestling figures, dinosaurs; hammering toys; aggressive characters and puppets such as a witch or shark;

- toys and art supplies for creative expression and emotional release: e.g. sand, water, clay, paints, collage, sculpting;

- construction toys: construction toys such as Lego ${ }^{\circledR}$ or $\mathrm{K}^{\prime} \mathrm{Nex}^{\circledR}$ allow a child to demonstrate goal attainment and closure, providing a sense of structure for the child who perhaps feels he/she has none in his environment [19];

- games: e.g. card games, age-appropriate video games; although these games do not meet the criteria for unstructured, therapeutic playthings and should be used in moderation, they are worthwhile for developing initial rapport with and between children and can be seen by some as 'safer' or less risky than other materials because they do not require imagination or exploration; games and computer software that encourage creative expression, such as animated movie making, journal writing, and virtual exploration software, can be selected. 


\section{Conclusion}

Play is a universal need. Decades of research has documented that play has a crucial role in the optimal growth, learning and development of children [20]. In the midst of childhood suffering, whether related to illness and medical treatment, palliative care, bereavement, or other hardships, play and expressive activities serve as a powerful antidote. Recognition of the child's need for play and the use of techniques to meet this need are an essential component of every child's development and care, for play has the potential to heal the spirit even when medicine cannot heal the body.

\section{References}

1 Schaefer CE: What is play and why is it therapeutic?; in Schaefer CE (ed): The Therapeutic Powers of Play. Northvale, Aronson, 1991, pp 1-15.

2 Freud A: The role of bodily illness in the mental life of children; in Eissler R, Freud A, Hartmann H, Kris E (eds): The Psychoanalytic Study of the Child. New York, International Universities Press, 1952, pp 69-81.

3 Erikson EH: Childhood and Society, ed 2, revised. New York, Norton, 1963.

4 Axline VM: Play Therapy. New York, Ballentine, 1969.

5 DelPo EG, Frick S: Directed and nondirected play as therapeutic modalities. Child Health Care 1988;16:261-267.

6 Neuman E: The Elements of Play. New York, MSS Information, 1971.

7 Bolig R: Play in hospital settings; in Yawkey T, Pellegrini A (eds): Child's Play: Developmental and Applied. Hillsdale, Erlbaum, 1984, pp 323-345.
8 Bolig R: Play in children's health-care settings; in Rollins JA, Bolig R, Mahan CC (eds): Meeting Children's Psychosocial Needs across the Health-Care Continuum. Austin, Pro-Ed, 2005, pp 77-117.

9 Child Life Council: http://www.childlife. org.

10 Landreth G: Play Therapy: The Art of the Relationship. Muncie, Accelerated Development, 1991.

11 Rode DC: Building bridges within the culture of pediatric medicine: the interface of art therapy and child life programming. Art Ther J Am Art Ther Assoc 1995;2:104-110.

12 Erikson EH: Childhood and Society, ed 2, revised. New York, WW Norton \& Co, 1963.

13 Landreth G: Play Therapy: The Art of the Relationship. Muncie, Accelerated Development, 1991
14 Axline VM: Play Therapy. New York, Ballentine, 1969.

15 Tsao LL: How much do we know about the importance of play in child development? Child Educ 2002;78:230-233.

16 Worden W: Grief Counseling and Grief Therapy: A Handbook for the Mental Health Practitioner. New York, Springer, 1982.

17 Wolfelt A: Healing the Bereaved Child. Fort Collins, Companion Press, 1996.

18 Landreth G: Play Therapy: The Art of the Relationship. Muncie, Accelerated Development, 1991.

19 Norton C, Norton B: Reaching Children through Play Therapy: An Experiential Approach. Denver, Pendleton Clay, 1997.

20 Isenberg J, Quisenberry N: Play: Essential for all children. A position paper of the Association for Childhood Education International, 2002 (retrieved December 1, 2005 from http://www.acei.org/playpaper.htm). 